\title{
Wave Patterns in the Ground: Case Studies Related to Vibratory Sheet Pile Driving
}

\author{
Fanny Deckner $[$ Kenneth Viking $\cdot$ Staffan Hintze
}

Received: 26 January 2016/ Accepted: 17 June 2017 / Published online: 29 June 2017

(C) The Author(s) 2017. This article is an open access publication

\begin{abstract}
Vibrations due to pile and sheet pile driving are known to cause discomfort for people, as well as damage to nearby buildings and structures. To enable prediction of ground vibration levels it is important to acknowledge the wave patterns induced in the ground to correctly determine which attenuation model to adopt. This paper presents wave patterns in the ground due to vibratory sheet pile driving based on field measurements from three case studies. The results show different wave patterns in the ground. At the ground surface the wave patterns are elliptical, resembling Rayleigh waves. At depth in the soil the wave patterns are instead strongly polarized in different directions, indicating the presence of $\mathrm{P}$ - and $\mathrm{S}$-waves. Moreover, wave patterns tend to become more irregular with increasing distance from the source. This paper contributes to an improved understanding of wave patterns in the ground during vibratory sheet pile driving, forming a platform for the development of a reliable prediction model.
\end{abstract}

F. Deckner - S. Hintze

KTH Royal Institute of Technology, Brinellvägen 23, 10044 Stockholm, Sweden

F. Deckner $(\bowtie) \cdot S$. Hintze

NCC AB, Vallgatan 3, 17080 Solna, Sweden

e-mail: fanny.deckner@ncc.se

K. Viking

Swedish Transport Administration, Trafikverket, 17290 Sundbyberg, Sweden
Keywords Wave patterns - Ground vibrations · Sheet pile $\cdot$ Vibratory driving $\cdot$ Case study

\section{Introduction}

Current international trends in town planning lead to new constructions being raised in close proximity to existing houses and structures, as well as on land with poor ground conditions. Consequently, piles and sheet piles are more and more commonly used in urban construction projects. However, vibrations due to pile and sheet pile driving are known to cause problems such as discomfort for people and even damage to nearby property (Wiss 1967; Attewell and Farmer 1973; Head and Jardine 1992; Hintze 1994; Hope and Hiller 2000). To maintain a sustainable development and secure the continued use of sheet piles in urban areas reliable prediction of the vibration level, prior to construction, is crucial. Currently there is a lack of a reliable, easy-to-use prediction model (Deckner et al. 2012). For future reliable prediction of vibration level during sheet pile driving it is important to adopt a proper attenuation model corresponding to the wave pattern in the ground.

During sheet pile driving vibrations are transferred from the sheet pile to the surrounding soil. At the toe, both an S-wave and a P-wave front are generated as the pile penetrates the soil. Along the shaft an S-wave front is produced due to friction between the pile and the soil. Deckner et al. (2015b) 
proposes the addition of a $\mathrm{P}$-wave front emanating from the shaft during vibratory driving to account for a horizontal motion of the sheet pile, see Fig. 1. When P- and S-wave fronts reach the free ground surface Rayleigh waves develop. Further, ground vibrations due to a construction vibration source are commonly divided into near-field and far-field. In the near-field both $\mathrm{P}-, \mathrm{S}$ - and Rayleigh waves are present. In the far-field it is a general consensus that vibrations mainly consist of Rayleigh waves (Head and Jardine 1992; Masoumi 2008; Whenham 2011; Arcos et al. 2011). As part of their study of ground vibrations caused by vibratory sheet pile driving, Athanasopoulos and Pelekis (2000) reconstructed particle displacement paths from field measurements at the ground surface. They observed that the shape of the displacement path was similar to Rayleigh wave motion at $2.40 \mathrm{~m}$ from the source, while the motion was instead predominantly vertical at greater distances. Whenham (2011) also produced particle velocity paths from measurements of vibrations at the ground surface during vibratory sheet pile driving. Similar to Athanasopoulos and Pelekis (2000), Whenham (2011) recognized that the wave patterns were elliptical, resembling Rayleigh wave motion, at shorter distances (about $<5 \mathrm{~m}$ ); however, at greater distances the velocity path was instead predominantly horizontal. A plausible reason for the vibrations being predominately vertical respectively horizontal at larger distances in Athanasopoulos and
Fig. 1 Wave transfer from sheet pile to soil during vibratory driving, modified after Deckner et al. (2015b)

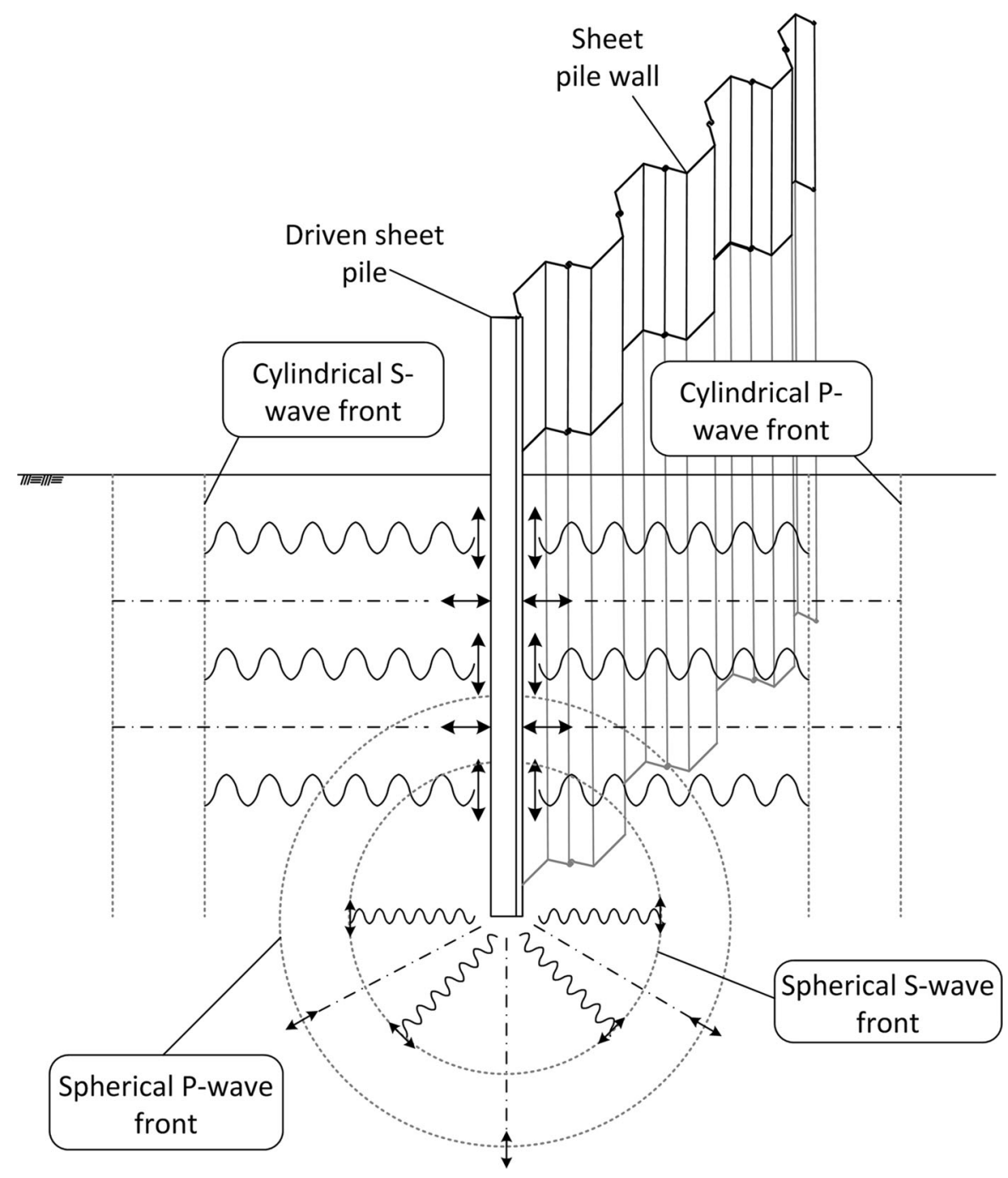


Pelekis (2000) and Whenham (2011) could be that the vertical vibrations are generally higher in Athanasopoulos and Pelekis (2000) and the other way around in Whenham (2011). This, in turn, could be due to the difference in driving frequency (16 respectively $35 \mathrm{~Hz}$ ), as Whenham (2011) observed that the lower the driving frequency the higher the vertical vibrations.

Previous studies (Athanasopoulos and Pelekis 2000; Whenham 2011) of wave pattern in the soil during sheet pile driving are limited in their extent and mainly constitute minor parts of wider studies. The results presented in the studies are in agreement regarding development of Rayleigh waves at short distances from the sheet pile. However, regarding vibrations further from the pile the results are inconclusive. Furthermore, it can be noted that there is a lack of studies focusing on the wave propagation at depth, probably due to absence of available field data. Therefore, wave patterns in the ground during vibratory sheet pile driving are not fully evaluated in the literature. In this study wave patterns in the ground during vibratory sheet pile driving are investigated on the basis of three field tests. The difference in wave pattern at depth and on the surface is analysed and discussed. The overall aim is to clarify wave patterns during vibratory sheet pile driving in order to improve the understanding of the particle motion during driving and enable future prediction of ground vibration levels.

\section{Wave Pattern in the Ground Related to Vibratory Sheet Pile Driving}

The wave patterns in the ground mainly depends on the type of wave/waves present, which in turn is highly dependent upon the transfer of vibrations from sheet pile to soil, and the soil conditions. In this section expected wave patterns in the ground during vibratory sheet pile driving is presented in the light of previous studies.

Table 1 Summary of theories regarding how far from the source Rayleigh waves develop

\begin{tabular}{|c|c|c|c|}
\hline Researchers & Expression & $\begin{array}{l}\text { Distance with given } \\
\text { values }(\mathrm{m})\end{array}$ & Developed for \\
\hline Wolf $(1994)^{a}$ & $r=\frac{\lambda_{R}}{2}$ & 1.43 & $\begin{array}{l}\text { Vertical point load acting on the ground } \\
\text { surface in unbounded soil }\end{array}$ \\
\hline $\begin{array}{l}\text { Athanasopoulos and Pelekis (2000), } \\
\text { originating from Dowding (1996) }\end{array}$ & $r=\frac{c_{R} d}{\sqrt{c_{P}^{2}-c_{R}^{2}}}$ & 0.67 & Unspecified pile driving in unspecified soil \\
\hline Massarsch and Fellenius (2008) & $r_{\text {crit }}=\tan \theta_{\text {crit }} \times d$ & 0.67 & Impact driven piles in unspecified soil \\
\hline
\end{tabular}

${ }^{a}$ In Wolf (1994) this is the boundary between near- and far-field, Rayleigh waves are present in the near-field; however, it is not until the far-field that they are fully developed

Table 2 Chosen input parameters to identify Rayleigh wave development and near-field distance

\begin{tabular}{|c|c|c|c|}
\hline Parameter & Name & Chosen value & Explanation \\
\hline$d$ & Pile toe depth & $10 \mathrm{~m}$ & $\begin{array}{l}\text { Assuming that the pile toe is the main vibration source along } \\
\text { the pile (Deckner et al. 2015a) }\end{array}$ \\
\hline$c_{S}$ & Shear wave speed & $100 \mathrm{~m} / \mathrm{s}$ & $\begin{array}{l}\text { Chosen from tabular values given in Head and Jardine (1992) } \\
\text { for soft clay }\end{array}$ \\
\hline$c_{P}$ & Primary wave speed & $1500 \mathrm{~m} / \mathrm{s}$ & $\begin{array}{l}\text { Chosen from tabular values given in Head and Jardine (1992) } \\
\text { for soft clay }\end{array}$ \\
\hline$c_{R}$ & Rayleigh wave speed & $100 \mathrm{~m} / \mathrm{s}$ & $\begin{array}{l}\text { Taken from the assumption that in practical cases the } \\
\text { difference between } c_{S} \text { and } c_{R} \text { is negligible (Massarsch and } \\
\text { Fellenius 2008) }\end{array}$ \\
\hline$\lambda_{R}$ & Rayleigh wave length & $2.86 \mathrm{~m}$ & $\begin{aligned}= & c_{R} / f=100 / 35, \text { a frequency of } 35 \mathrm{~Hz} \text { is assumed which is a } \\
& \text { common driving frequency for vibratory driven sheet piles } \\
& \text { (Deckner et al. 2015a) }\end{aligned}$ \\
\hline
\end{tabular}


The most common wave types in an elastic half space are primary waves (P-waves), secondary waves (S-waves) and Rayleigh waves. P-waves are characterized by a push-pull motion in the direction of the wave, while the S-wave is described by a motion perpendicular to the propagation direction. S-waves are often divided into two perpendicular components, $\mathrm{SH}$-waves and SV-waves (Kramer 1996). SH-waves are $\mathrm{S}$-waves in which the particles oscillate in a horizontal plane. While SV-waves are S-waves in which the particles oscillate in a vertical plane. Rayleigh waves are a combination of $\mathrm{P}$ - and $\mathrm{S}$-waves with a retrograde ellipsoidal particle motion. Thus, $\mathrm{R}$-waves involve both vertical and horizontal particle motion.
During sheet pile driving vibrations are transferred from the pile to the soil, both at the toe and along the shaft (Athanasopoulos and Pelekis 2000; Masoumi and Degrande 2008). At the toe both an S-wave and a $\mathrm{P}$-wave front is generated as the pile penetrates the soil. Along the shaft an $\mathrm{S}$-wave front is generated due to friction between pile and soil. This general notion is correct if the sheet pile only vibrates in the vertical direction. However, in several previous publications (Viking 2002; Masoumi 2008; Whenham 2011; Deckner et al. 2015a) it has been shown that the sheet pile vibrates extensively in both the vertical and horizontal directions. Hence, Deckner et al. (2015b) proposes the addition of a $\mathrm{P}$-wave front emanating from the shaft during vibratory sheet pile driving to

Table 3 Summary of theories regarding near-field distance

\begin{tabular}{lll}
\hline Researchers & Near-field distance & Developed for \\
\hline Arcos et al. (2011) & Horizontal displacement: $8.05 \mathrm{~m}$ & Point source acting on the ground surface in sand \\
& Vertical displacement: $0.65 \mathrm{~m}$ & \\
Masoumi (2008) & $<4 \lambda_{R}=11.44 \mathrm{~m}$ & Vibratory driven sheet piles in unspecified soil \\
Wolf (1994) & $\lambda_{R} / 2=1.43 \mathrm{~m}$ & Vertical point source acting on the ground surface in unbounded soil \\
\hline
\end{tabular}

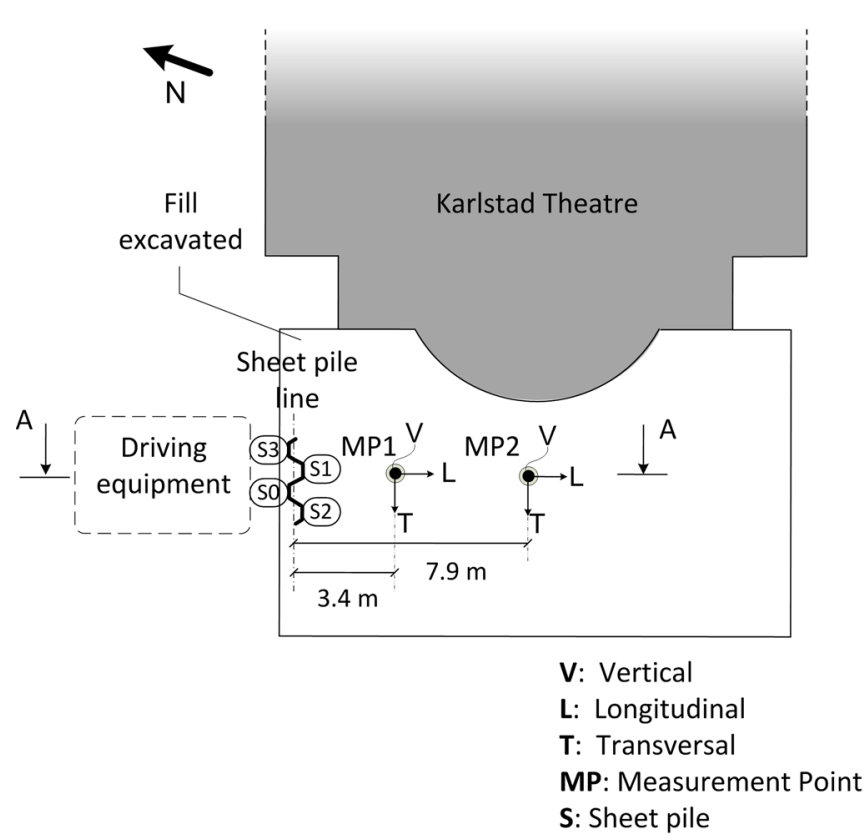

(a)



(b)

Fig. 2 Test layout for the field test in Case 1; a plan view and $\mathbf{b}$ side view including geotechnical conditions 
account for the horizontal motion of the sheet pile during driving; see Fig. 1. In Deckner et al. (2015b) it was also shown that vibrations to a high degree are transferred to adjoining sheet piles when driven in interlock.

The soil conditions also affect the wave pattern to a high degree. As is pointed out by Richart et al. (1970) a half-space of multiple layers, which is almost always the case at real life construction sites, results in a complex array of waves as they are reflected and refracted at each interface. The difficulty of a large number of different waves and wave fronts occurring in layered soil has since been pointed out by several authors (Head and Jardine 1992; Kramer 1996; Masoumi et al. 2007; Athanasopoulos-Zekkos et al. 2013).

Theories regarding how far from the pile/sheet pile Rayleigh waves develop have been presented over the years (Wolf 1994; Athanasopoulos and Pelekis 2000; Massarsch and Fellenius 2008). According to both Attewell and Farmer (1973) and Head and Jardine (1992) it is not clear if true Rayleigh waves develop over the short distances that are generally a concern for vibration problems due to pile driving. However, results from field tests presented in Athanasopoulos and Pelekis (2000) and Whenham (2011), both in similar soil conditions with mainly clayey and silty sand, show Rayleigh waves as near as $2.4 \mathrm{~m}$ from the source. The available theories have been summarized in Table 1, where $r$ represents the horizontal distance from source to Rayleigh wave development. With chosen input data (see Table 2) a distance has also been calculated from the expressions. It can be seen that even though the expressions have been developed for different sources the calculated distances all lie within the same range, from approximately 0.7 to

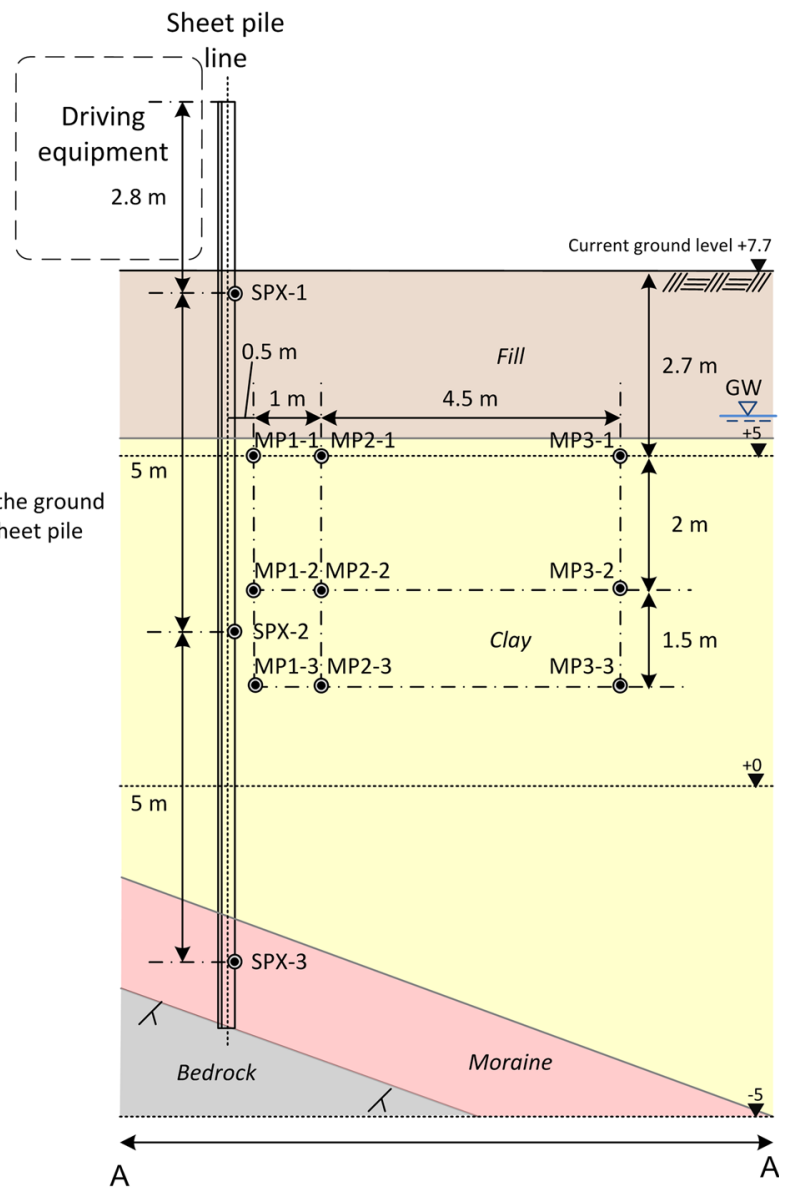

(b)

Fig. 3 Test layout for the field test in Case 2; a plan view and $\mathbf{b}$ side view including geotechnical conditions 
$1.5 \mathrm{~m}$. This is in line with the field test observations of Athanasopoulos and Pelekis (2000) and Whenham (2011), and it clearly indicates that Rayleigh waves are developed within a distance that is definitely of concern for vibration problems.

Ground vibrations due to a vibration source are commonly divided into near-field and far-field (Head and Jardine 1992; Wolf 1994; Whenham 2011; Arcos et al. 2011). In the near-field both surface and body waves are present and energy is dissipated due to plastic deformations in the soil. In the far-field vibrations mainly consist of surface waves and the soil behaviour is elastic. Several theories have been presented over the years regarding at what distance from the source the division between near- and farfield is located, the so-called near-field distance. The theories have been summarized in Table 3. In the table it is also stated what conditions the near-field distance have been developed for. Table 3 shows that there is a range between about 1.5-12 $\mathrm{m}$ in which the near-field distance can be located using the input parameters listed in Table 2. This large discrepancy indicates that the near-field distance is not fully investigated and moreover that it probably varies significantly with background conditions and settings.

\section{Evaluation of Case Studies}

Within the framework of a corporate research project at NCC Construction and KTH Royal Institute of Technology in Sweden, with the aim of increasing the understanding of ground vibrations due to pile and sheet pile driving, three field tests have been performed; Case 1-Karlstad theatre 2010, Case 2Solna tramway 2013 and Case 3-Värta Harbour 2014.

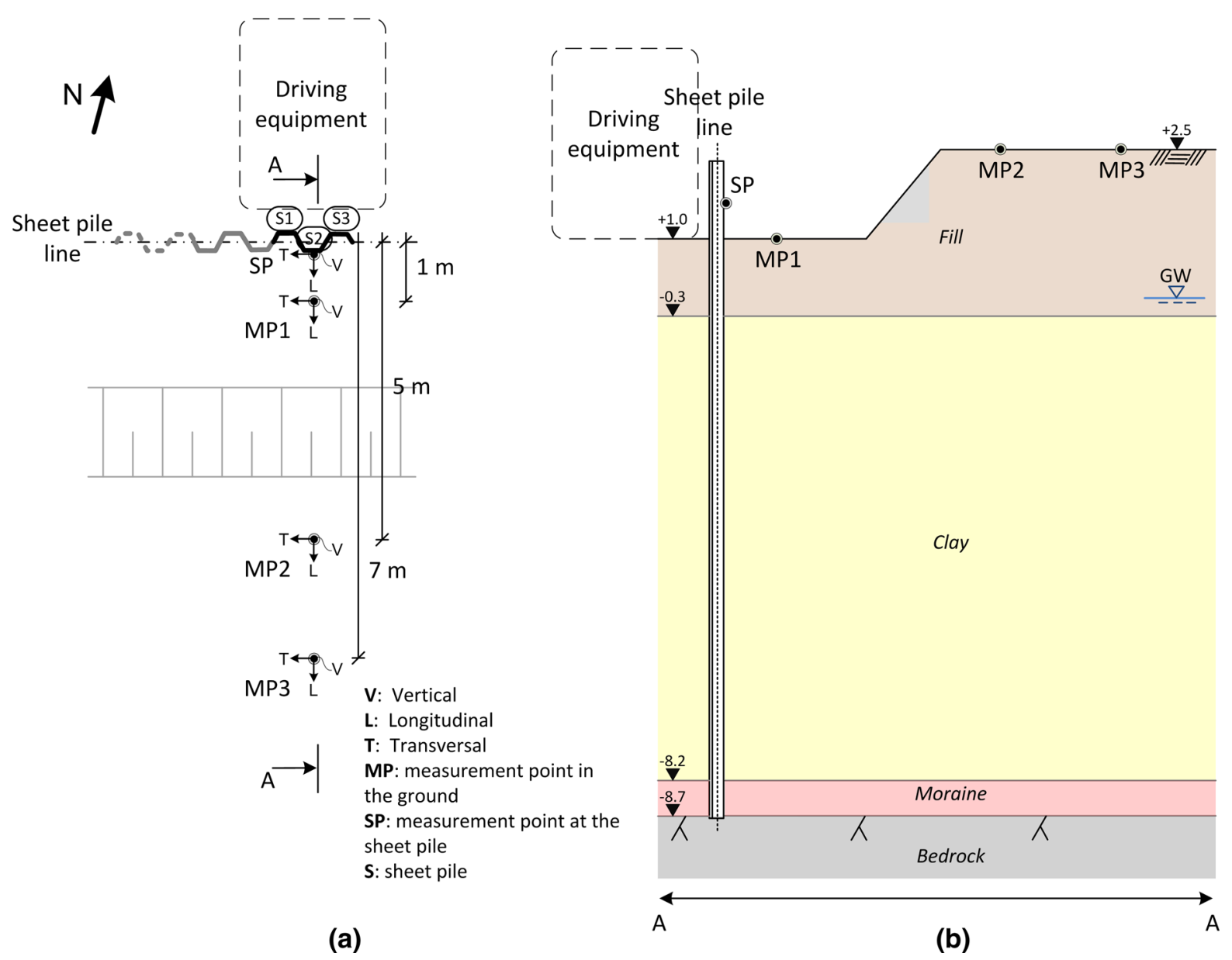

Fig. 4 Test layout for the field test in Case 3; a plan view and $\mathbf{b}$ side view including geotechnical conditions 
In this paper the three cases are briefly explained and the results are analysed with respect to wave pattern in the ground. For further information about the tests and additional results the reader is referred to Lidén (2012) for Case 1, Guillemet (2013) and Deckner et al. (2015a) for Case 2, and Daniels and Lovén (2014) for Case 3.

\subsection{Background and Description}

First a brief description of the test site and the measurement layout is presented for each case, thereafter typical results are illustrated.

\subsubsection{Case 1-Karlstad Theatre 2010}

In preparation for the extension of Karlstad theatre, vibrations were measured during vibratory sheet pile driving. The field test was conducted as part of a trial sheet pile driving aiming to establish if it was possible to use vibratory driven sheet piles in regard to environmental impact concerning settlements and vibrations of the theatre itself and nearby buildings.

Karlstad is situated in the west of Sweden and the theatre is located in the middle of town on the river bank of Klarälven. Figure $2 b$ illustrates the characteristic soil profile along with the setup of the measurement and driving equipment. The uppermost layer of the soil profile consists of fill. At the time of the field study, the fill layer was excavated from the area in which the sheet piles were to be installed and the measurements performed, as can be seen in Fig. 2. Beneath the fill the natural soil consists of loose, finegrain river sediments, mainly sand and silt with thin courses of gyttja and plant residues present. Below this

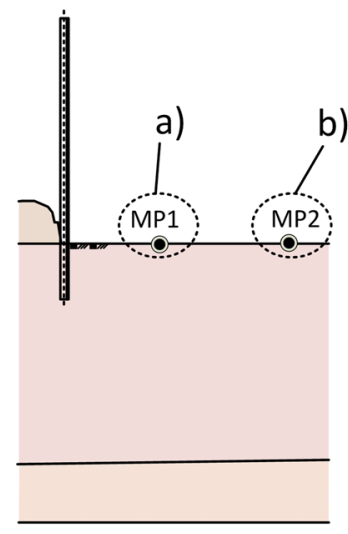

Penetration depth

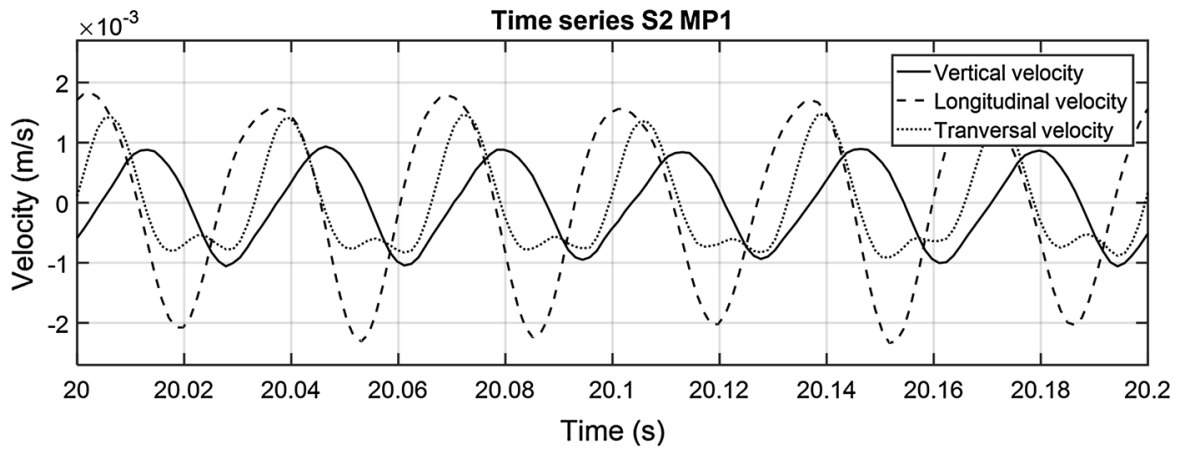

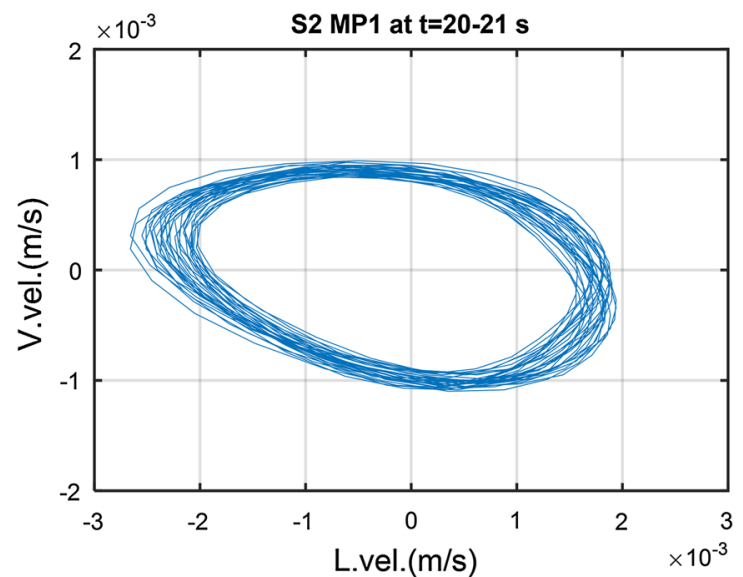

(a)

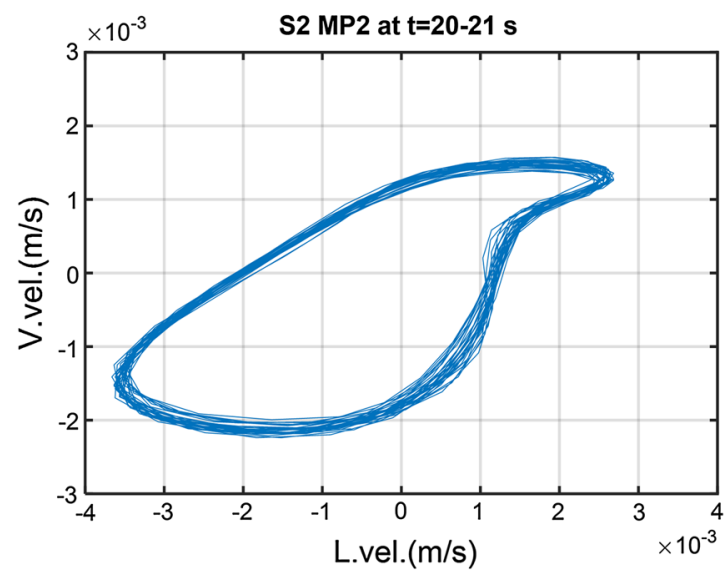

(b)

Fig. 5 Particle velocity paths from Case 1 during driving of S2 from; a MP1 and b MP2 
layer the soil consists of moderately firm, glacial clay. The groundwater level was measured to approximately $3 \mathrm{~m}$ below original ground surface.

Case 1 constituted the driving of four sheet piles and measurements were performed during the driving of the last three. First a single sheet pile was driven (S0); thereafter sheet piles $\mathrm{S} 1, \mathrm{~S} 2$ and S3 were driven, meaning that all measurements correspond to driving the sheet pile into interlock with another profile (see Fig. 2a). The $12 \mathrm{~m}$ long sheet piles were driven to a depth of about $10.5-11 \mathrm{~m}$, thus only entering the first layers of sand and silty sand. Ground vibrations were measured using two tri-axial geophones, at two separate locations, as illustrated in Fig. 2. A vibrator of type Dieseko
2316VM was used to drive the sheet piles to desired depth. The vibrator itself was a free hanging model; however, in this case it was mounted to a leader. The driving frequency was set to $28 \mathrm{~Hz}$.

\subsubsection{Case 2-Solna Tramway 2013}

When constructing a new tramway in Solna, north of Stockholm, a full-scale field test was performed in May 2013. Vibrations were measured on sheet piles during driving as well as on already installed sheet piles. Vibrations were also recorded at depth in the ground. The field test was conducted with the aim of studying the sheet pile-soil interaction and the vibration transfer further from the source.
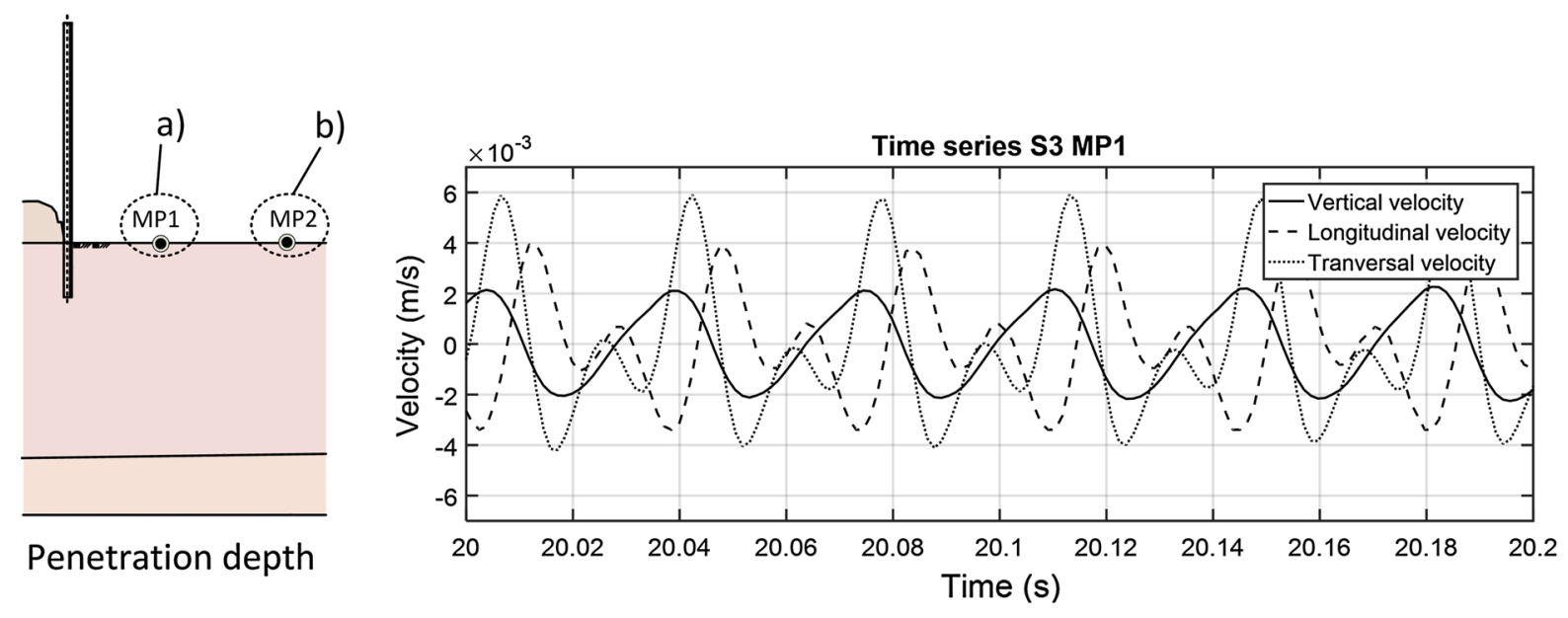

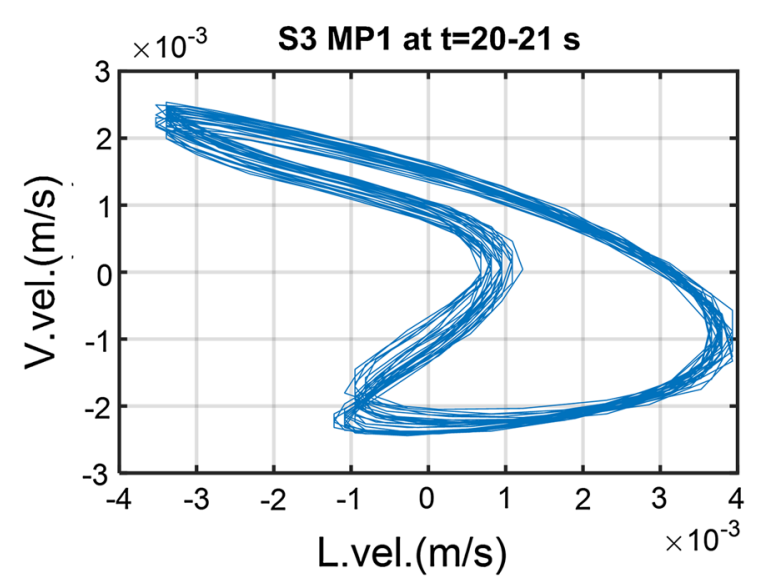

(a)

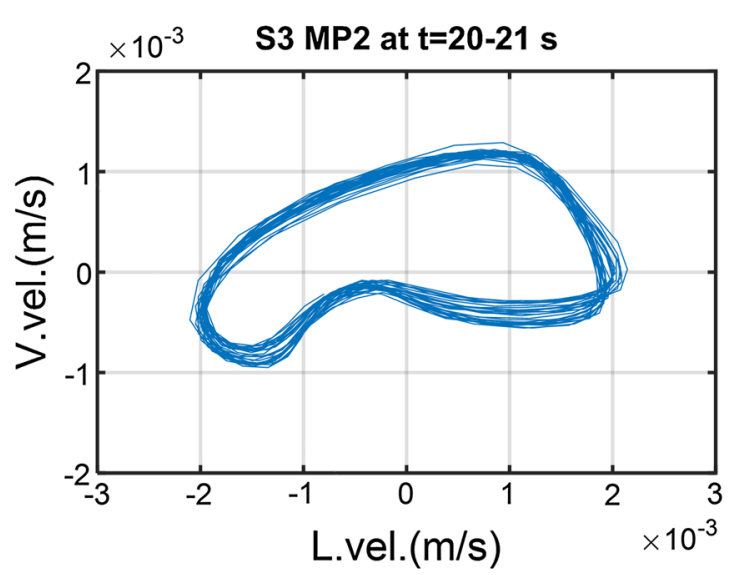

(b)

Fig. 6 Particle velocity paths from Case 1 during driving of S3 from; a MP1 and b MP2 
The geotechnical conditions on the test site are characterized by fill, overlaying clay on moraine on top of bedrock, see Fig. 3b. The layering slopes towards the south. The ground water level is situated approximately $2 \mathrm{~m}$ below the ground surface.

Triaxial accelerometers were positioned on three locations on three of the driven sheet piles and also on three different depths in the ground, at three different distances from the sheet pile line, see Fig. 3. In total seven sheet piles were driven (S1-S7); the first one was driven free while the others were driven in interlock. The first five sheet piles (13.8 m long) were driven down to the bedrock, while the last two $(11 \mathrm{~m}$ long) were driven to the top of the moraine layer. The driving equipment consisted of a Liebherr piling and drilling rig with a leader mounted vibrator. The sheet piles were driven with a frequency of $35 \mathrm{~Hz}$.

\subsubsection{Case 3-Värta Harbour 2014}

In April 2014 ground and sheet pile vibrations, caused by vibratory driven sheet piles as well as drilled RDpile wall, were measured during driving. The field test was performed at Värta Harbor in central Stockholm and the aim was to compare vibrations caused by vibratory driven sheet piles and RD-pile wall.

The geotechnical conditions at the test site are typical for the Stockholm area with fill overlaying clay on moraine on top of bedrock, see Fig. 4b. The groundwater table has been measured to correspond to a depth of $2.5 \mathrm{~m}$ below the original ground surface.

Figure 4 shows the principal test layout, including geotechnical conditions. Triaxial accelerometers were positioned on one of the driven sheet piles and on three locations at the ground surface (MP1, MP2 and MP3).

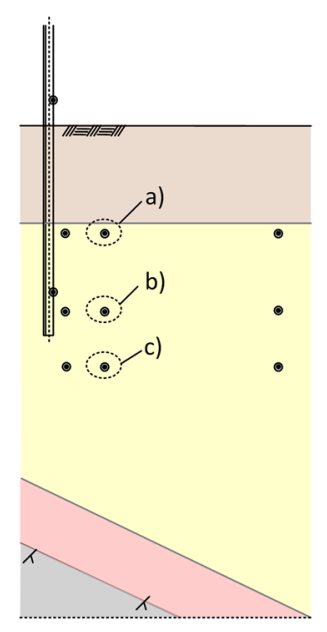

Penetration depth

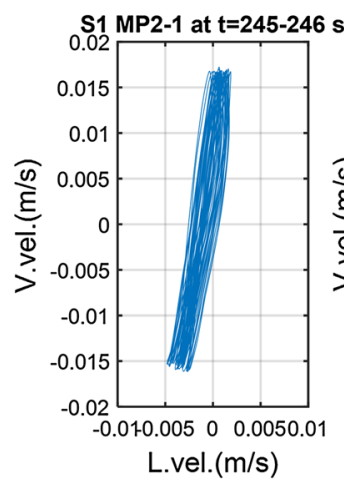

(a)

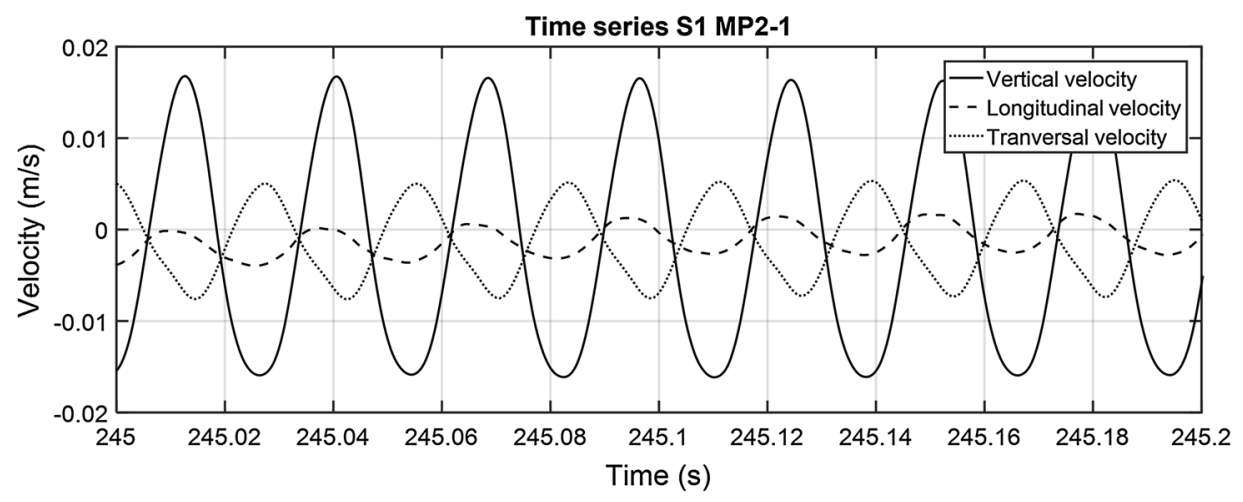

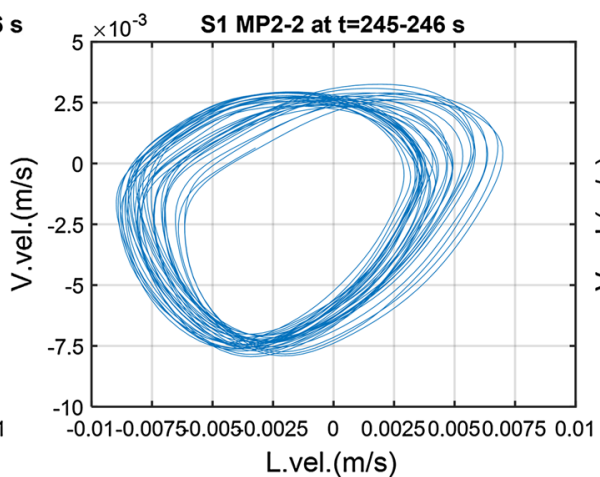

(b)

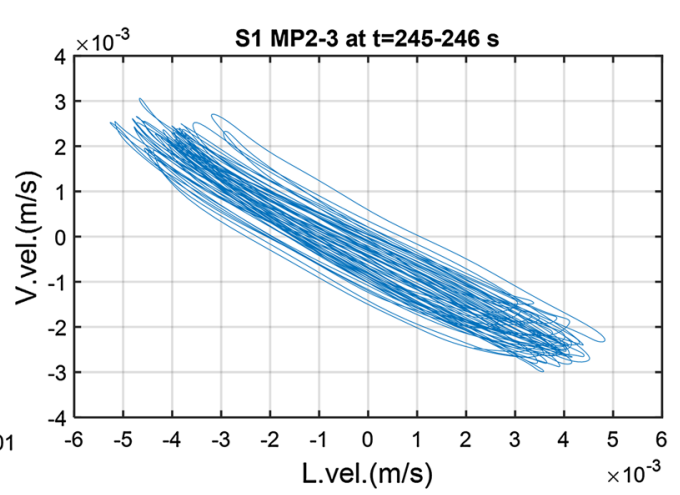

(c)

Fig. 7 Particle velocity paths for Case 2 during driving of S1 from; a MP2-1, b MP2-2 and c MP2-3 
Due to the geometry of the test site, the first measurement point (MP1) was positioned at a level of $+1.0 \mathrm{~m}$ above sea level while the second and third measurement points (MP2 and MP3) were positioned outside of the excavation area at a level of $+2.5 \mathrm{~m}$. Three $12 \mathrm{~m}$ long sheet piles were driven in the field test (S1-S3), as a continuation of a longer sheet pile wall. The sheet piles were driven to a depth of approximately $10 \mathrm{~m}$ using a leader mounted vibrator from ABI. The driving frequency was remained constant at around $36 \mathrm{~Hz}$.

\subsection{Results}

The results are presented separately for the three cases, focusing on the understanding of wave patterns in the ground during driving. The vertical and longitudinal velocity components are plotted against each other to enable analysis of the particle motion and wave pattern in the ground during driving. The particle displacement paths are illustrated using particle velocity. Using velocity has the advantage of reducing the artificial amplification of high frequencies, which occurs when plotting acceleration, while at the same time avoiding the accumulated error of double-integration to obtain displacements. To keep the figures clear the soil particle velocities are plotted over a $1 \mathrm{~s}$ time period. To enhance understanding of the results time signals for the plotted time period are added for each particle velocity path. A small sketch indicating penetration depth at the specified time period is also included.

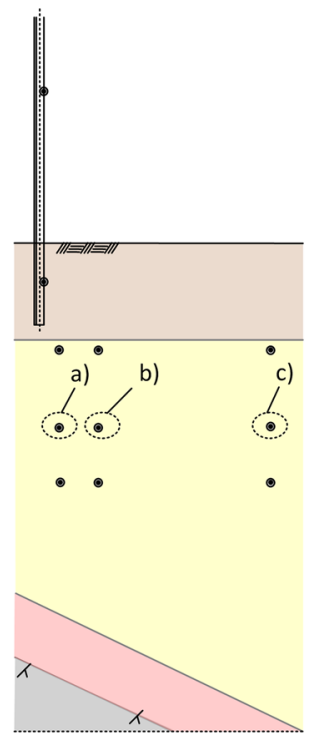

Penetration depth

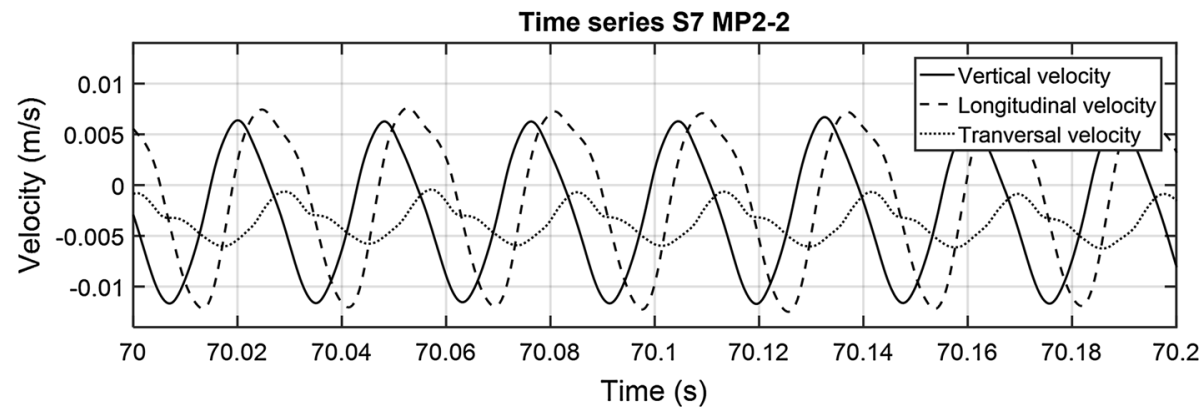

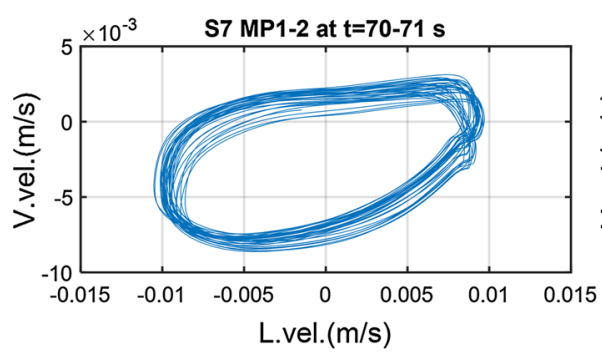

(a)

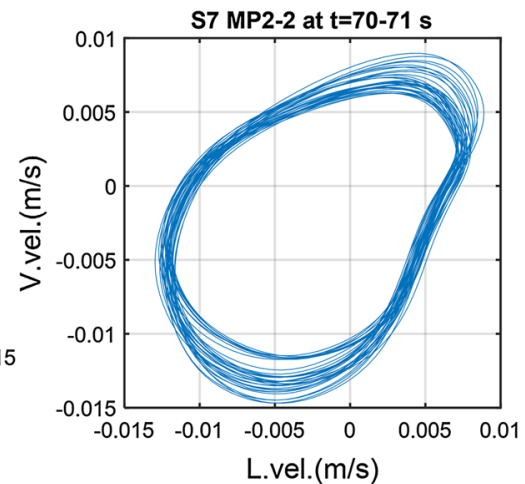

(b)

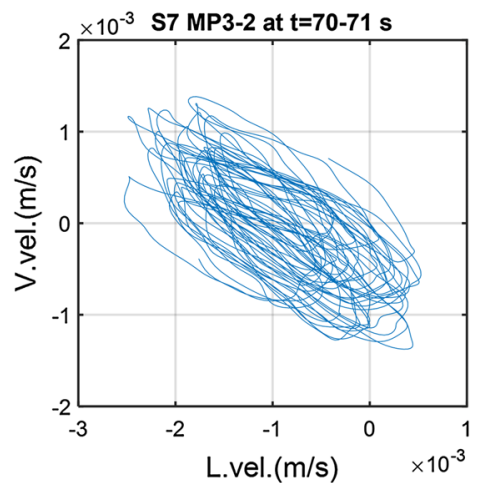

(c)

Fig. 8 Particle velocity paths for Case 2 during driving of S7 from; a MP1-2, b MP2-2 and c MP3-2 


\subsubsection{Case 1-Karlstad Theatre 2010}

In Fig. 5, typical particle velocity paths from Case 1 are displayed. The shape is fairly round in MP1 and a bit more elliptical in MP2. It can be noted that throughout the driving of S2 the particle displacement paths were slightly more gathered in MP2 than in MP1 (cf. Fig. 5a, b).

When S3 is driven the shapes of the particle displacement paths are more jagged and irregular than during driving of S1 and S2, as can be seen in Fig. 6, which display particle velocity paths recorded at MP2.

\subsubsection{Case 2-Solna Tramway 2013}

Typical particle velocity paths from the recordings in Case 2, at least in MP1 and MP2, are displayed in Fig. 7, which shows velocities in MP2 at level 1, 2 and 3 , during driving of $\mathrm{S} 1$. The paths are elliptical in shape but also more or less polarized in different directions.
For all series there is a clear trend that the recordings in MP3 give very messy shapes when plotted as particle velocity paths. In Fig. 8 this is clearly visible when particle velocity paths during driving of S1 in MP1-1, MP2-1 and MP3-1 are plotted during $1 \mathrm{~s}$ between 70 and $71 \mathrm{~s}$.

\subsubsection{Case 3-Värta Harbour 2014}

Figure 9 shows typical particle velocity paths from Case 3. The figure displays the velocity paths of MP1, MP2 and MP3 during driving of S1. As can be seen the paths from MP1 are much clearer than in MP2 and MP3. The paths from MP1 are largely elliptical; see Fig. 9a. In MP2 and MP3 the paths are more irregular; see Fig. 9b, c. The trend is a round respectively elliptical pattern but for each period the path is moved.

During driving of S2 and S3, it is more common with complex path shapes; see e.g. Fig. 10, than during driving of S1. The complex paths indicate the
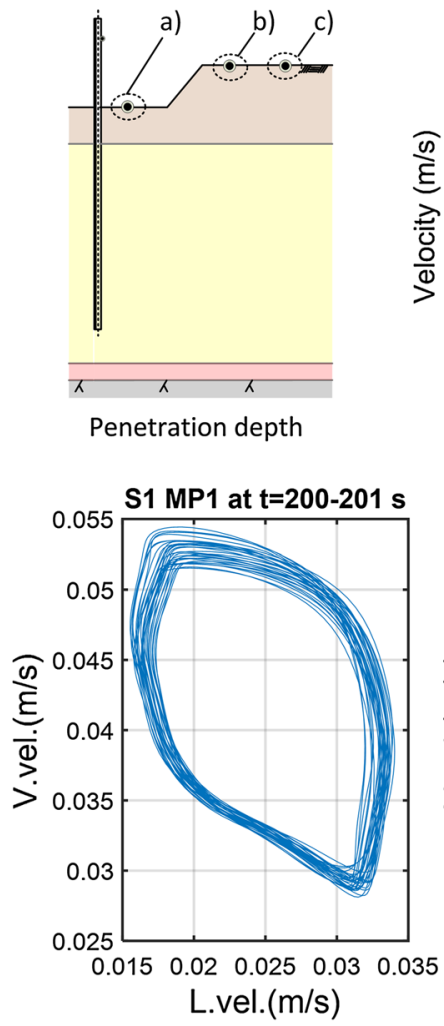

(a)

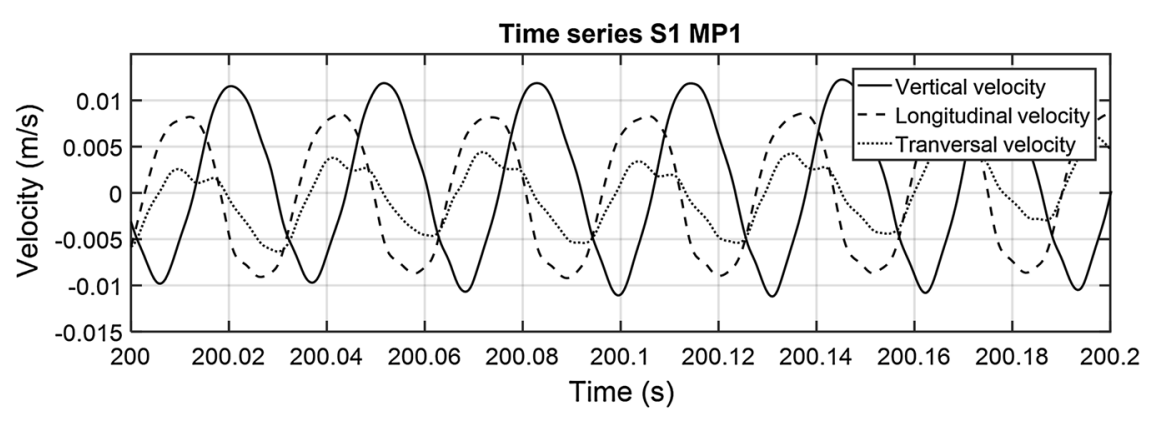

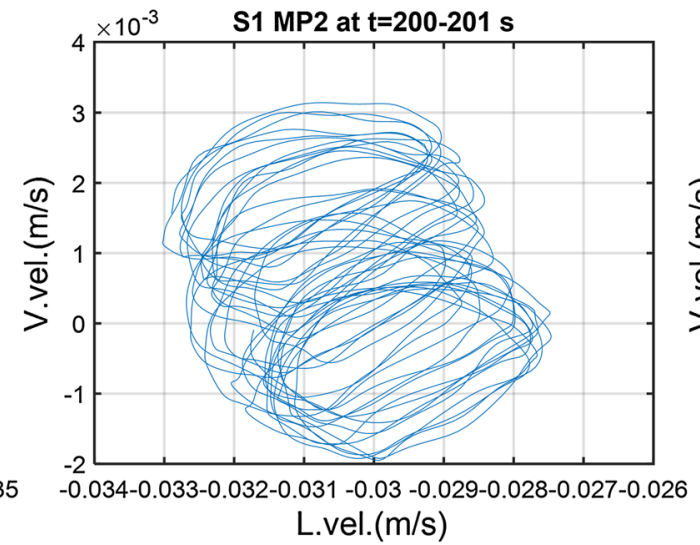

(b)

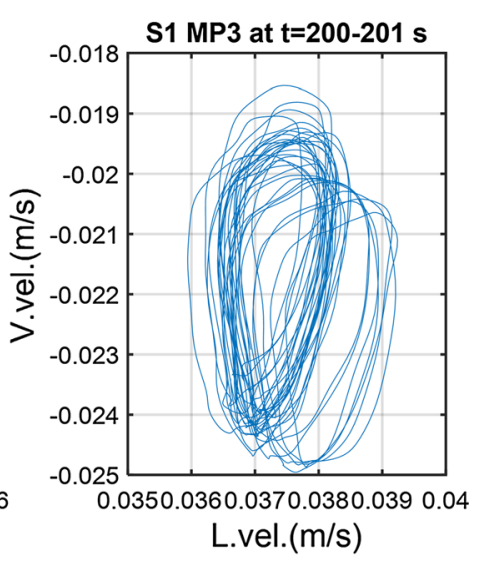

(c)

Fig. 9 Particle velocity paths for Case 3 during driving of S1 from; a MP1, b MP2 and c MP3 

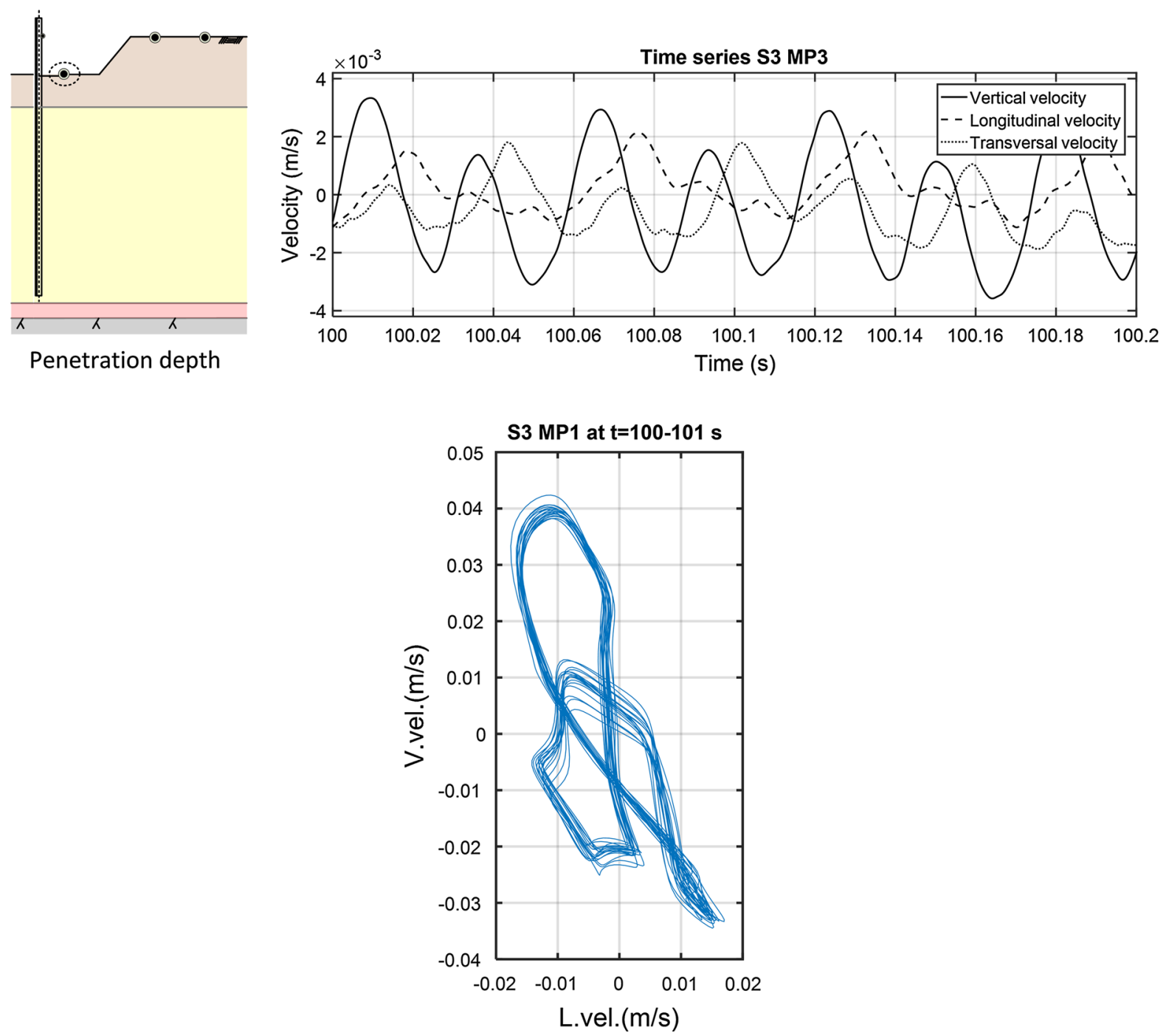

Fig. 10 Particle velocity path for Case 3 during driving of S3 from MP1

presence of higher frequencies apart from the driving frequency.

\section{Analysis and Discussion}

To facilitate comparison and analysis of the three presented cases a summarizing figure has been compiled; see Fig. 11. The figure visualizes differences between the cases regarding geometry, position of measurement points, ground conditions and typical results.

In Case 1 an elliptical shape can be observed in both measurement points (3.4 and $7.9 \mathrm{~m}$ from source). The elliptical shape indicates that it is a Rayleigh wave. The same shape is seen in Case 3 for MP1, which is located $1 \mathrm{~m}$ from the source (cf. Figs. 5 and 9a). This agrees well with the theories in previous literature regarding the development of Rayleigh waves, which are summarized in Table 1, that they are developed even at short distances from the source. The results are also in line with results presented in Athanasopoulos and Pelekis (2000) and Whenham (2011).

In Case 2, on the other hand, the results are also elliptical but often much more polarized in different directions (see Fig. 11), which would indicate that it is not true Rayleigh waves but instead P- or S-waves. A plausible explanation is that for the measurements at 

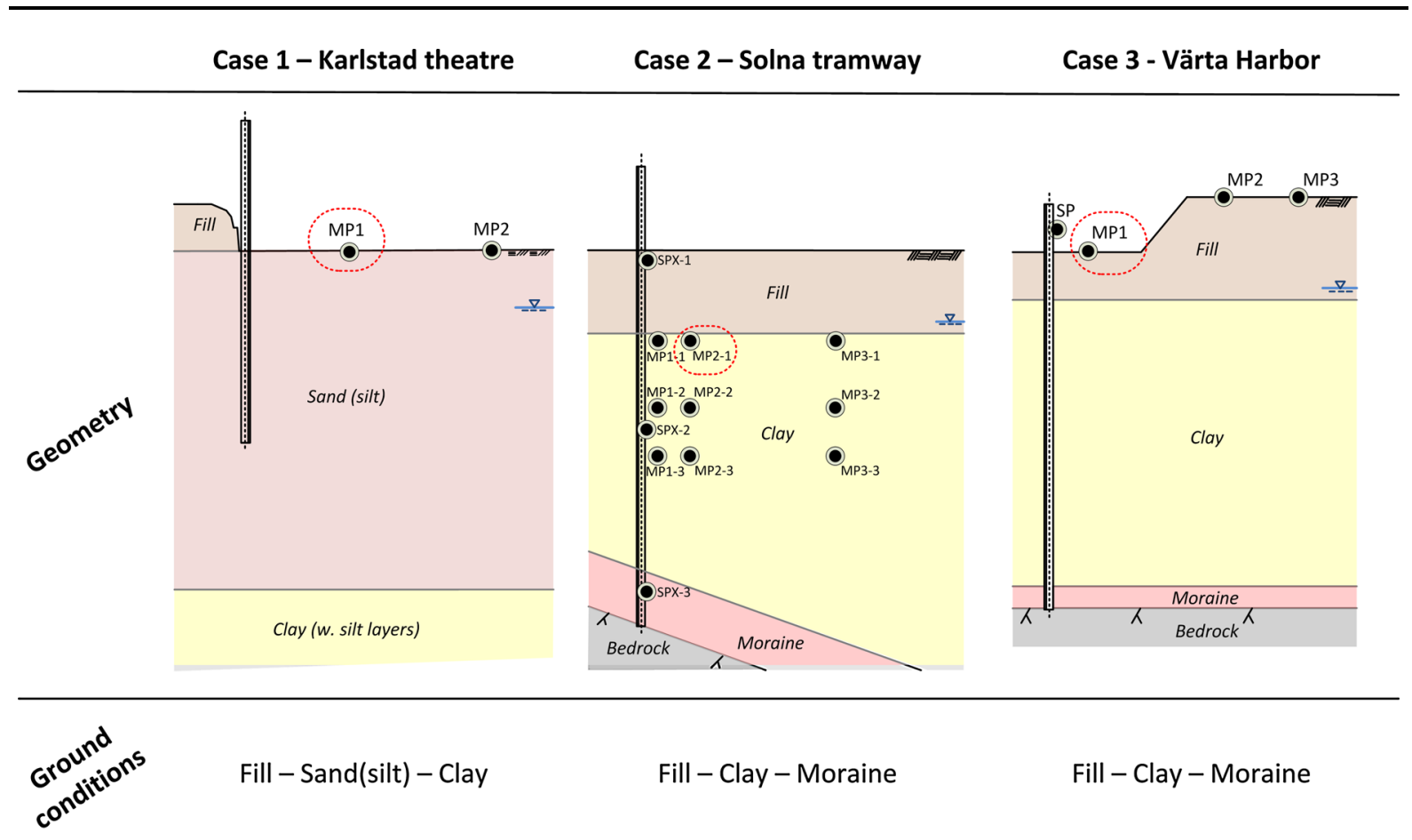

$$
\text { Fill - Sand(silt) - Clay }
$$

Fill - Clay - Moraine

Fill - Clay - Moraine
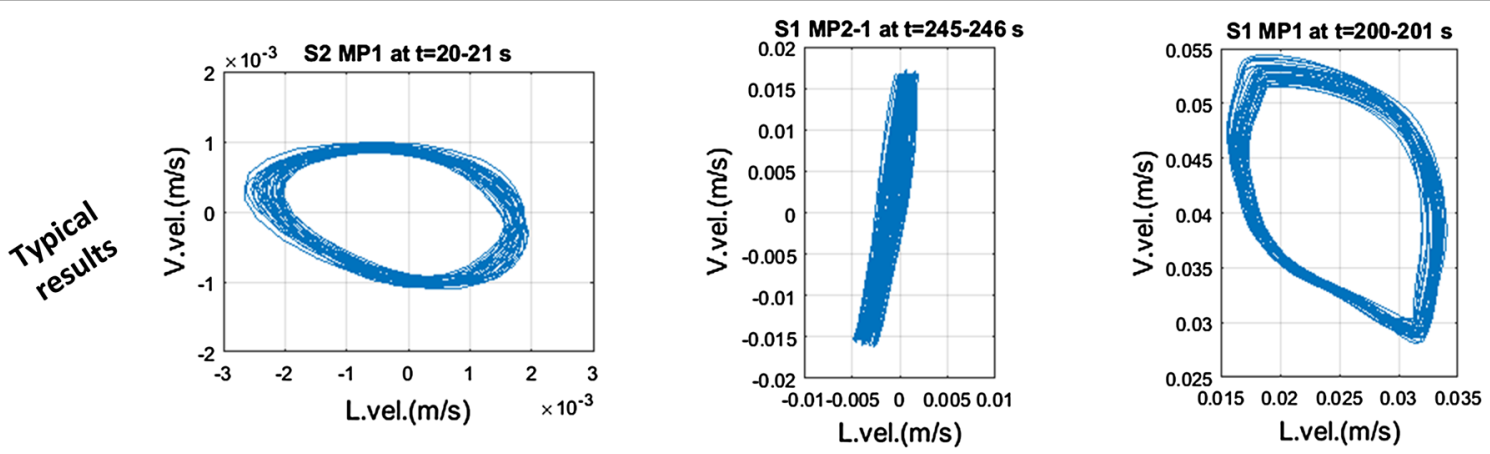

Fig. 11 Summarizing comparison between the three case studies, including geometry, ground conditions and typical particle velocity paths

depth it is P- and S-waves that are being recorded and not Rayleigh waves. Richart et al. (1970) derived relationships for the horizontal and vertical Rayleigh wave amplitudes as a function of depth, $d$, wave length, $\lambda$, and Poisson's ratio, $v$, see Fig. 12. Level 1 for the measurement points in Case 2 is situated at a depth of $2.7 \mathrm{~m}$, level 2 at $4.7 \mathrm{~m}$ and level 3 at $6.2 \mathrm{~m}$. With an estimated Rayleigh wave length of $2.86 \mathrm{~m}$ (see Table 2) a quota of $d / \lambda$ would give $0.94,1.64$ respectively 2.17. Plotting these in Fig. 12, showing horizontal and vertical amplitude of Rayleigh waves, would give that the Rayleigh wave amplitudes are very small at Level 1 and at Level 2 and 3 it is unlikely that any Rayleigh waves are present. Hence, the theoretical relationships for Rayleigh wave amplitude with depth presented in Richart et al. (1970) is applicable for the development of Rayleigh waves due to sheet pile driving. It can also be concluded that the elliptical paths in Case 2 are the results of a mix of $\mathrm{P}-, \mathrm{SH}-$ and $\mathrm{SV}$-waves.

In Fig. 13 it is illustrated how P-and S-waves from the toe and shaft would give rise to the wave pattern that is seen in Fig. 7 for MP2 at depth in Case 2. In MP2-1 the vertical polarization suggests that it is mainly shear waves emanating from the shaft. In MP22 the round shape is probably a combination of 


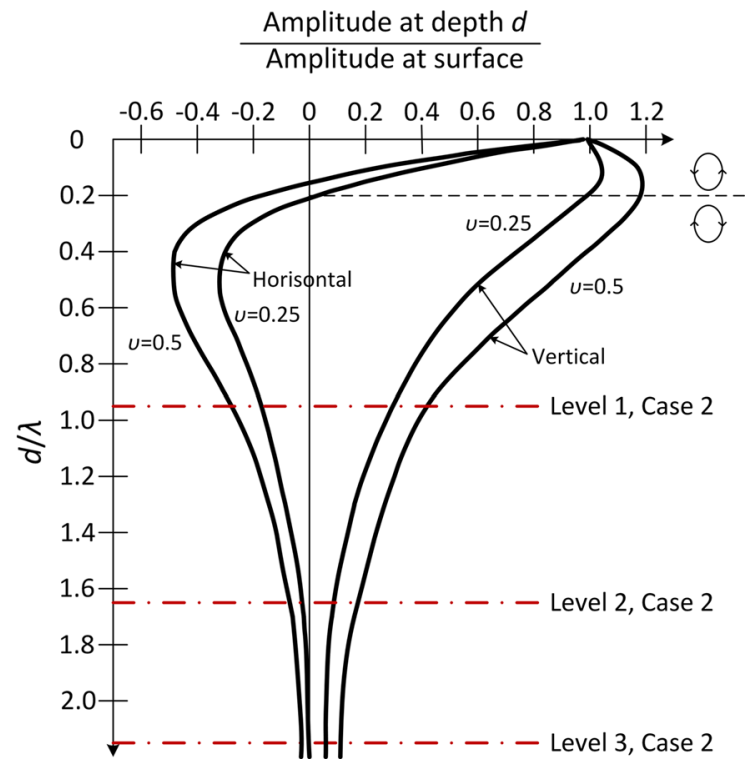

Fig. 12 Horizontal and vertical vibration amplitude of Rayleigh waves as a function of depth, Poisson's ratio and wave length (modified after Richart et al. 1970), with level 1, 2 and 3 from Case 2 marked

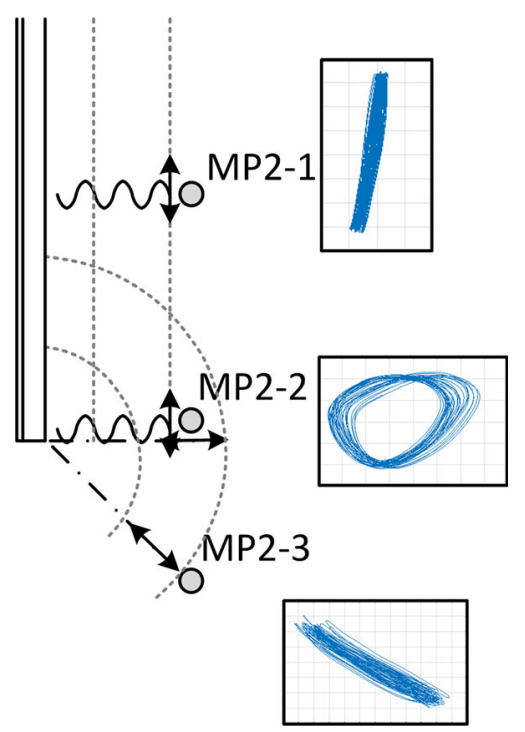

Fig. 13 Schematic illustration of wave patterns at depth in the soil due to $\mathrm{P}$ - and $\mathrm{S}$-waves emanating from the sheet pile toe and shaft

P-waves from the toe and S-waves from the shaft. In MP2-3 it is likely P-waves emanating from the toe that give rise to the wave pattern. This supports former theory regarding vibration transfer from sheet piles in soil during vibratory driving presented in e.g. Athanasopoulos and Pelekis (2000).
In both Case 2 and 3 the results are generally much clearer in MP1 and MP2 than in MP3, i.e. the wave patterns become more irregular as the distance from the source increases. A possible reason for this could be that at this distance there is a greater effect of reflections and refractions from soil layers and nearby structures than at MP1. All the three cases are located in urban environments, thus, apart from different soil layers, there are numerous underground structures in close proximity. Multiple layers in the soil have been identified by several researchers to influence wave pattern (Richart et al. 1970; Head and Jardine 1992; Kramer 1996, Masoumi et al. 2007; AthanasopoulosZekkos et al. 2013). Moreover, it would also seem likely that the presence of underground structures in the vicinity could impact the wave pattern. However, that the results in MP2 and MP3 are much more irregular than in MP1 in Case 3 can probably be due to the fact that MP2 and MP3 are positioned outside of the excavation. As previous literature is inconclusive regarding near-field distance (see Table 3) it is not known whether all or any of the measurement points are located within the near-field or not. It is therefore difficult to say if this trend of more irregular wave pattern with distance is related to the near-field-farfield boundary.

In Case 1 the reason for the more jagged and irregular shapes in Series 3 compared to Series 1 and 2 could be due to the fact that the sheet pile wall area is larger (cf. Figs. 5, 6). In Deckner et al. (2015b) it is shown that vibrations to a high degree are transferred to adjoining sheet piles. The larger area means that vibrations can emanate from more different points with slightly different distances to the measurement points, resulting in more disordered displacement paths.

In Case 3 the particle velocity paths display much more complex paths in Series 2 and 3, translating the presence of higher frequency overtones (cf. Figs. 9, 10). This could for example be due to interlock friction caused by worn locks or soil particles in the locks, pointed out by Viking (2002) as plausible reasons for additional vibrations during sheet pile driving.

\section{Conclusions}

A study of wave patterns in the ground during vibratory sheet pile driving has been conducted. This 
paper compares theories from literature with results from three field tests performed in Sweden between 2010 and 2014, in which vibrations have been recorded both on the ground surface and at depth in the ground during driving.

From the measurements performed at the ground surface the wave patterns have an elliptical shape, clearly resembling what would be expected of a Rayleigh wave. For the measurements at depth a clear pattern is more difficult to distinguish. Here, the particle motions are strongly polarized in diverse directions, which would indicate the presence of either P- or S-waves instead of Rayleigh waves. Nevertheless, from the direction of polarization it can be deduced that the displayed vibrations most likely emanate from the toe. The results in all of the three cases also display a clear tendency of a more disordered wave pattern as the distance from the source increases. A probable reason for this phenomenon is that further from the source the wave patterns are highly disturbed by reflected and refracted waves from nearby structures, resulting in more irregular wave patterns.

These new findings clarifies wave patterns in the ground during vibratory sheet pile driving and the main conclusions from the study of wave pattern during vibratory sheet pile driving can be summarized as:

- Rayleigh waves are developed at the surface as near as $1 \mathrm{~m}$ from the source.

- Wave patterns at depth are more irregular consisting of a mixture of $\mathrm{P}$ - and $\mathrm{S}$-waves emanating from the sheet pile toe and shaft.

- In urban construction projects the wave patterns tend to get more disturbed by reflected and refracted waves from nearby objects as the distance from the source increase.

Despite the difficulty of observing clear wave patterns in all cases this study contributes to an improved understanding of the wave pattern in ground during vibratory sheet pile driving. This knowledge is highly important for the future development of a prediction model, in which it will be crucial to recognize the wave pattern to ascertain that the correct attenuation model is adopted. The increased understanding of vibrations due to sheet pile driving along with improved prediction models will greatly benefit the construction industry through better technical solutions, reduced construction times and less environmental impact.

Acknowledgements The case studies presented in this paper is part of a joint research project between NCC Construction and KTH Royal Institute of Technology on vibrations due to pile and sheet pile driving. The authors would like to express their gratitude to the Development Fund of the Swedish Construction Industry, the Royal Institute of Technology and NCC Construction Sweden AB for the support of the project.

Open Access This article is distributed under the terms of the Creative Commons Attribution 4.0 International License (http:// creativecommons.org/licenses/by/4.0/), which permits unrestricted use, distribution, and reproduction in any medium, provided you give appropriate credit to the original author(s) and the source, provide a link to the Creative Commons license, and indicate if changes were made.

\section{References}

Arcos R, Romeu J, Balastegui A, Pàmies T (2011) Determination of the near field distance for point and line sources acting on the surface of an homogeneous and viscoelastic half-space. Soil Dyn Earthq Eng 31(7):1072-1074. doi:10. 1016/j.soildyn.2011.02.004

Athanasopoulos GA, Pelekis PC (2000) Ground vibrations from sheetpile driving in urban environment: measurements, analysis and effects on buildings and occupants. Soil Dyn Earthq Eng 19(5):371-387. doi:10.1016/S02677261(00)00008-7

Athanasopoulos-Zekkos A, Woods RD, Gkrizi A (2013) Effect of pile-driving induced vibrations on nearby structures and other assets. Technical Report No. RC-1600, Michigan Department of Transportation ORBP Number OR10-046

Attewell PB, Farmer IW (1973) Attenuation of ground vibrations from pile driving. Ground Eng 3(7):26-29

Daniels M, Lovén K (2014) Differences in ground vibrations generated from installation of bored and vibrated retaining walls - a field study. Master of Science thesis, KTH Royal Institute of Technology, Stockholm, Sweden

Deckner F, Viking K, Hintze S (2012) Ground vibrations due to pile and sheet pile driving — prediction models of today. In: Proceedings of the European young geotechnical engineers conference, Gothenburg, Sweden, 26-29 Aug 2012

Deckner F, Guillemet C, Viking K, Hintze S (2015a) Instrumentation system for ground vibration analysis during sheet pile driving. Geotech Test J 38(6):893-905. doi:10. 1520/GTJ20140275

Deckner F, Viking K, Hintze S (2015b) Vibration transfer during vibratory sheet pile driving - a full-scale field test. In: Proceedings of the 6th international conference on earthquake geotechnical engineering, Christchurch, New Zealand, 1-4 Nov

Dowding CH (1996) Construction vibrations. Prentice-Hall, Upper Saddle River 
Guillemet C (2013) Pile-soil interaction during vibratory sheet pile driving. Master of Science thesis, KTH Royal Institute of Technology, Stockholm, Sweden

Head JM and Jardine FM (1992) Ground-borne vibrations arising from piling. CIRIA, London, CIRIA Technical Note 142

Hintze S (1994) Risk analysis in foundation engineering with application to piling in loose friction soils in urban situations. Doctoral thesis, KTH Royal Institute of Technology, Stockholm, Sweden

Hope VS, Hiller DM (2000) The prediction of groundborne vibration from percussive piling. Can Geotech J 37(3):700-711. doi:10.1139/t99-130

Kramer SL (1996) Geotechnical earthquake engineering. Prentice-Hall, Englewood Cliffs

Lidén M (2012) Ground vibrations due to vibratory sheet pile driving. Master of Science thesis, KTH Royal Institute of Technology, Stockholm, Sweden

Masoumi HR (2008) Numerical modelling of free field vibrations due to pile driving. Doctoral thesis, Department of Civil Engineering, KU Leuven, Leuven, Belgium

Masoumi HR, Degrande G (2008) Numerical modelling of free field vibrations due to pile driving using a dynamic soil- structure interaction formulation. J Comp Appl Math 215(2):503-511. doi:10.1016/j.cam.2006.03.051

Masoumi HR, Degrande G, Lombaert G (2007) Prediction of free field vibrations due to pile driving using a dynamic soil-structure interaction formulation. Soil Dyn Earthq Eng 27(2):126-143. doi:10.1016/j.soildyn.2006.05.005

Massarsch KR, Fellenius BH (2008) Ground vibrations induced by impact pile driving. In: Prakash S (ed) Proceedings of the sixth international conference on case histories in geotechnical engineering, Arlington, USA, 11-16 Aug 2008

Richart FE, Woods RD, Hall JR (1970) Vibrations of soils and foundations. Prentice-Hall, Engelwood Cliffs

Viking K (2002) Vibro-driveability — a field study of vibratory driven sheet piles in non-cohesive soils. Doctoral thesis, KTH Royal Institute of Technology, Stockholm, Sweden

Whenham V (2011) Power transfer and vibrator-pile-soil interactions within the framework of vibratory pile driving. Doctoral thesis, University of Louvain, Belgium

Wiss JF (1967) Damage effects of pile driving vibration. Highway Research Board, Record 155, Washington, USA, pp 14-20

Wolf JP (1994) Foundation vibration analysis using simple physical models. Prentice Hall, Upper Saddle River 